1 Atmospheric Age Distribution of Primary and Secondary Inorganic Aerosols in a

\title{
Polluted Atmosphere
}

3 Qi Ying a, ${ }^{\text {a }}$, Jie Zhang a, Hongliang Zhang ${ }^{\text {b }}$, Jianlin $\mathrm{Hu}^{\text {c,de, }}$, Michael J. Kleeman ${ }^{\mathrm{f}}$

4 a Zachry Department of Civil Engineering, Texas A\&M University, College Station, Texas 577843 , USA

6 b Department of Environmental Science and Engineering, Fudan University, Shanghai, China

7 c Jiangsu Key Laboratory of Atmospheric Environment Monitoring and Pollution Control,

8 Nanjing, Jiangsu, China

9 Collaborative Innovation Center of Atmospheric Environment and Equipment, Nanjing, 10 Jiangsu, China

11 e School of Environmental Science and Engineering, Nanjing University of Information Science 12 and Technology, Nanjing, China.

$13{ }^{\mathrm{f}}$ Department of Civil and Environmental Engineering, University of California, Davis, 14 California 95616, USA

12 Figures and 1 Table;

* Corresponding author: Q. Ying (qying@civil.tamu.edu) 


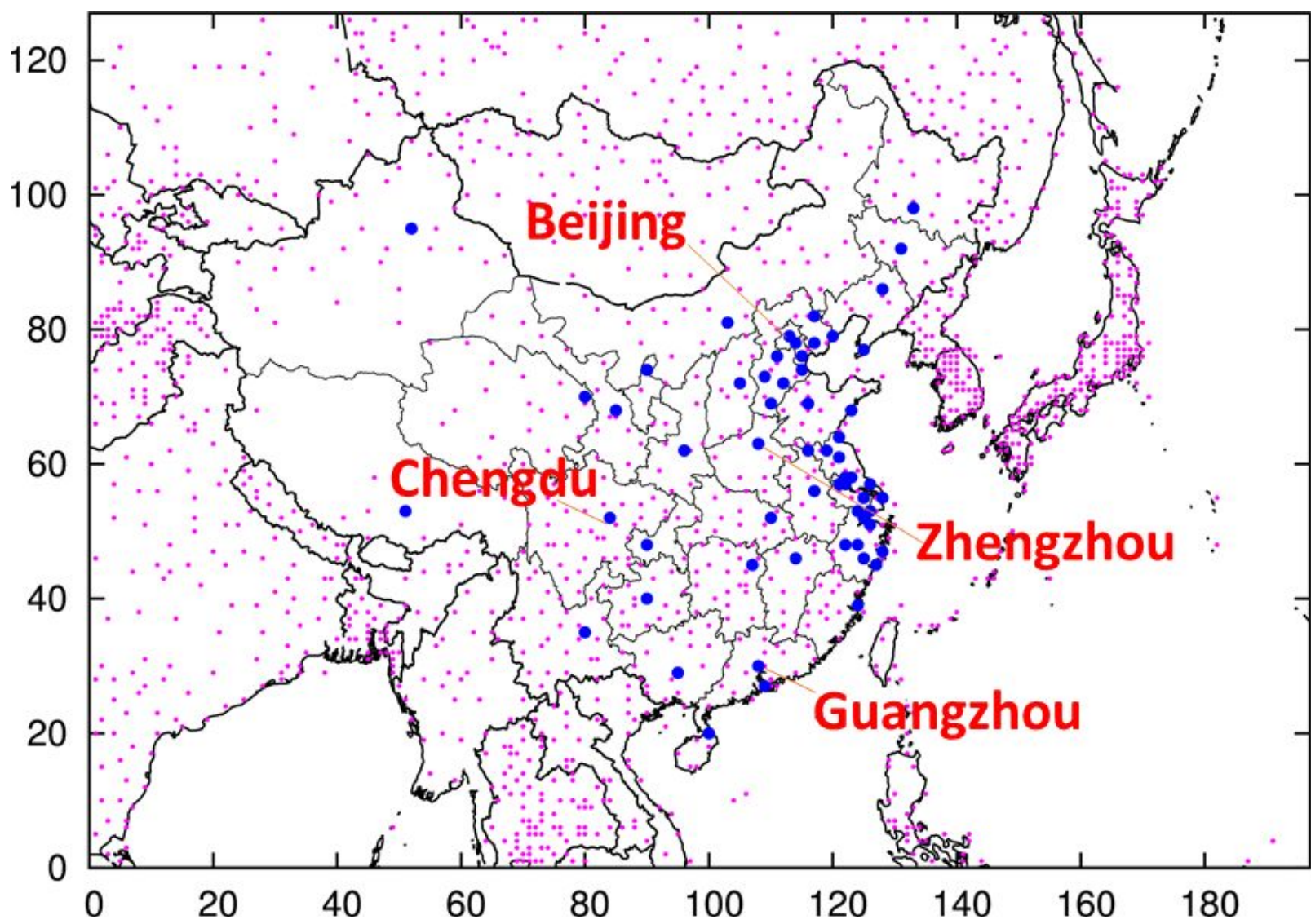

20 Figure S1. Air quality model domain and the location of the cities where PM2.5 data were

21 available from the US Consulate for January 2013. Blue dots are the location of the provincial

22 capitals, and the pink dots are locations where surface meteorology data were available. 
Beijing

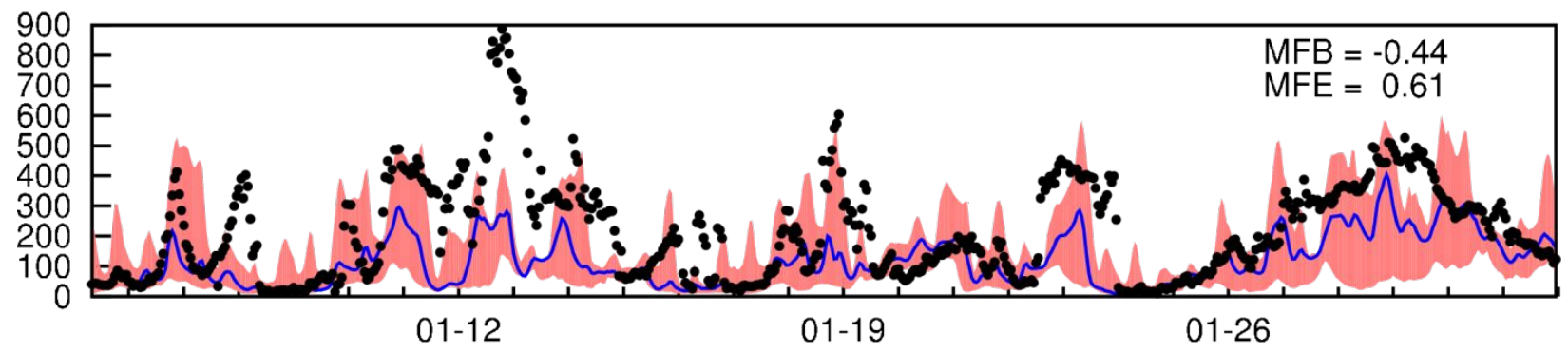

Shanghai

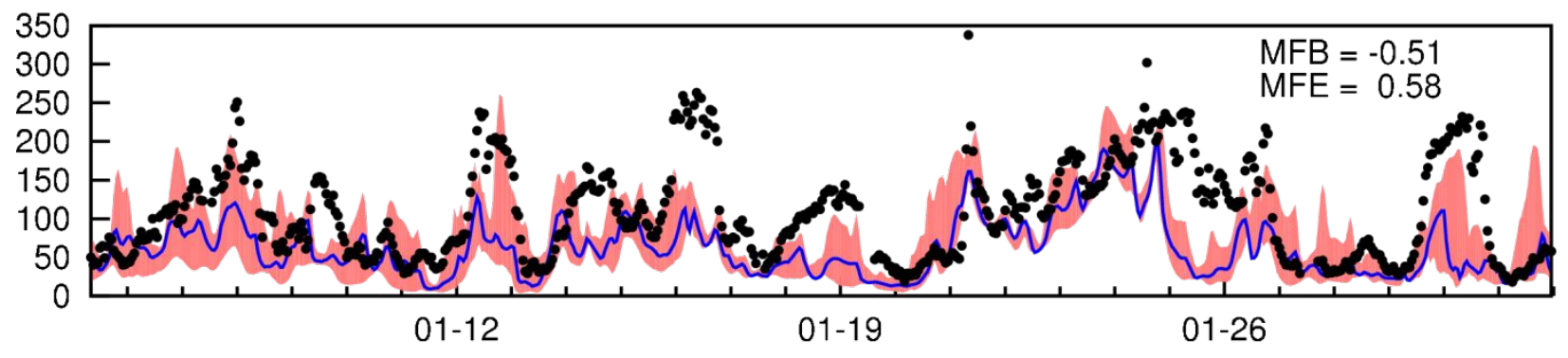

Guangzhou

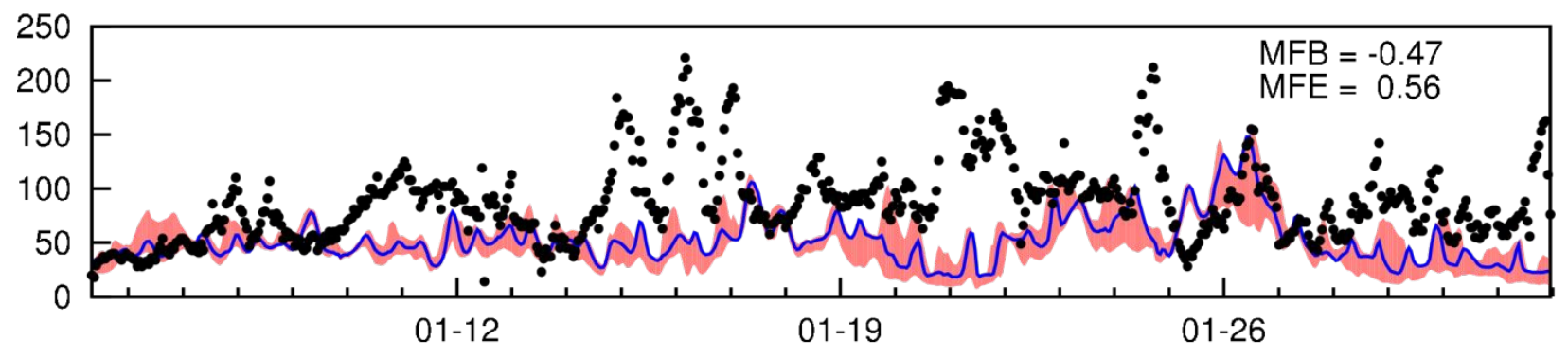

Chengdu

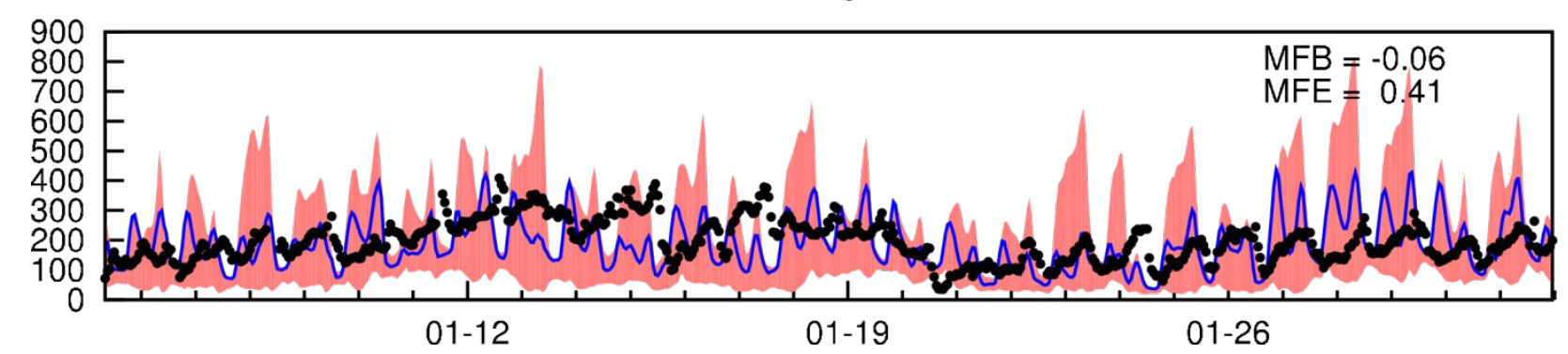

24 Figure S2. Predicted (blue lines) and observed (black dots) hourly $\mathrm{PM}_{2.5}$ concentrations in 4

25 Chinese cities in January 2013. The shaded areas represent the range of concentrations within the

26 nine grid cells $(3 \times 3)$ with the urban center in the middle. Units are $\mu \mathrm{g} \mathrm{m}^{-3}$. The mean fractional

27 bias (MFB) and mean fractional error (MFE) are calculated using the urban center predictions

28 with observations. 
PM_EC

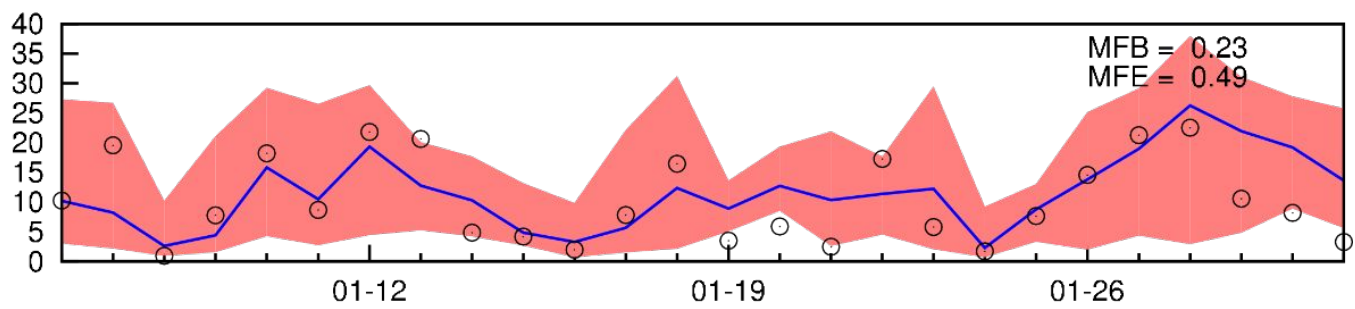

PM_OC

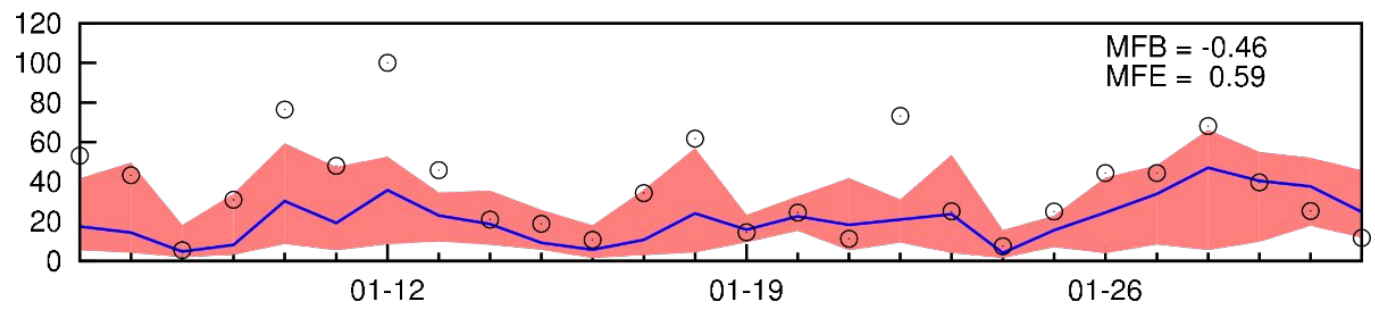

PM SO4

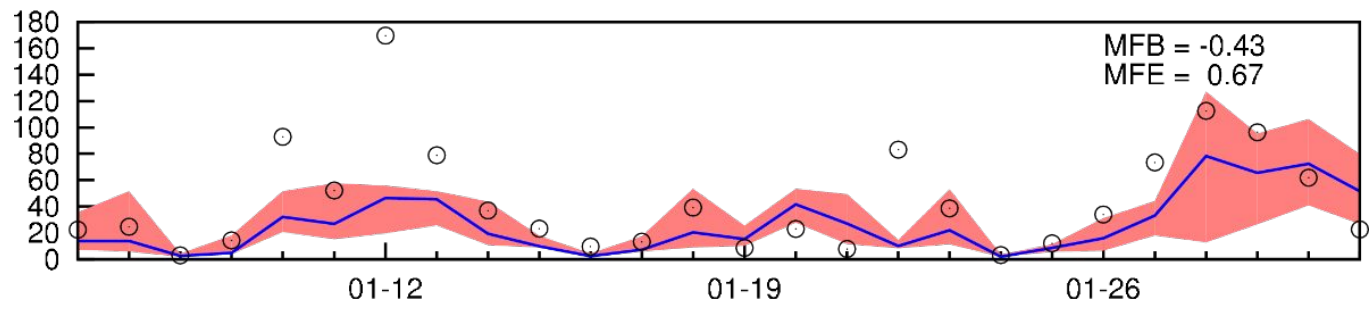

PM_NO3

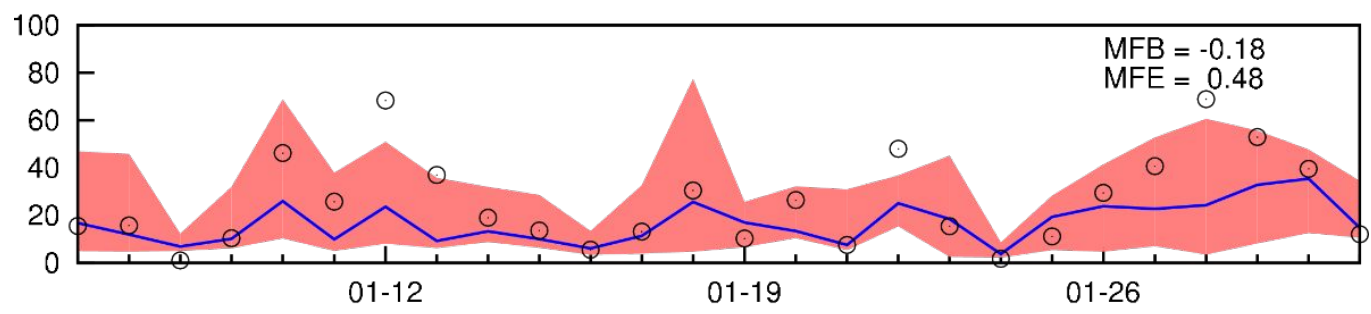

PM_NH4

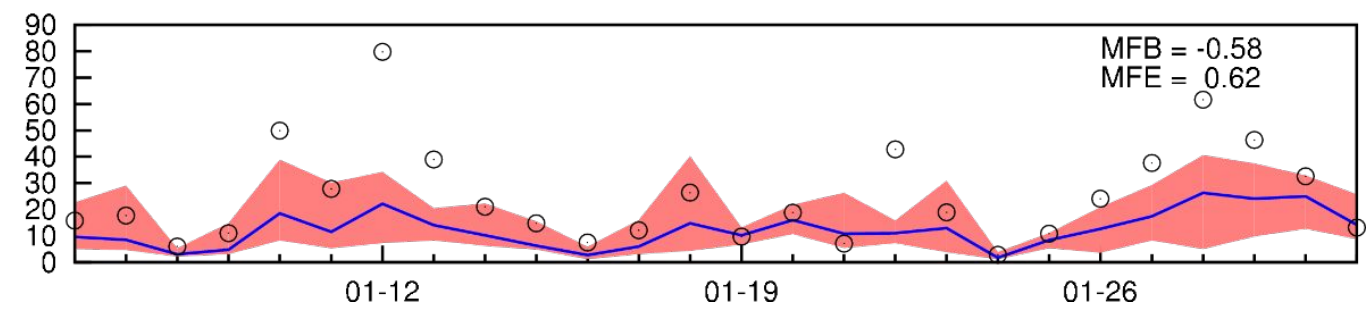

30 Figure S3. Predicted (blue lines) and observed (open circles) of $\mathrm{PM}_{2.5}$ chemical components (EC, $31 \mathrm{OC}, \mathrm{SO}_{4}{ }^{2-}, \mathrm{NO}_{3}{ }^{-}$and $\mathrm{NH}_{4}{ }^{+}$) in Beijing, January 2013. The shaded areas represent the range of 32 concentrations within the nine grid cells $(3 \times 3)$ with the urban center in the middle. Units are $\mu \mathrm{g}$ $33 \mathrm{~m}^{-3}$. The mean fractional bias (MFB) and mean fractional error (MFE) are calculated using the 34 urban center predictions with observations. 

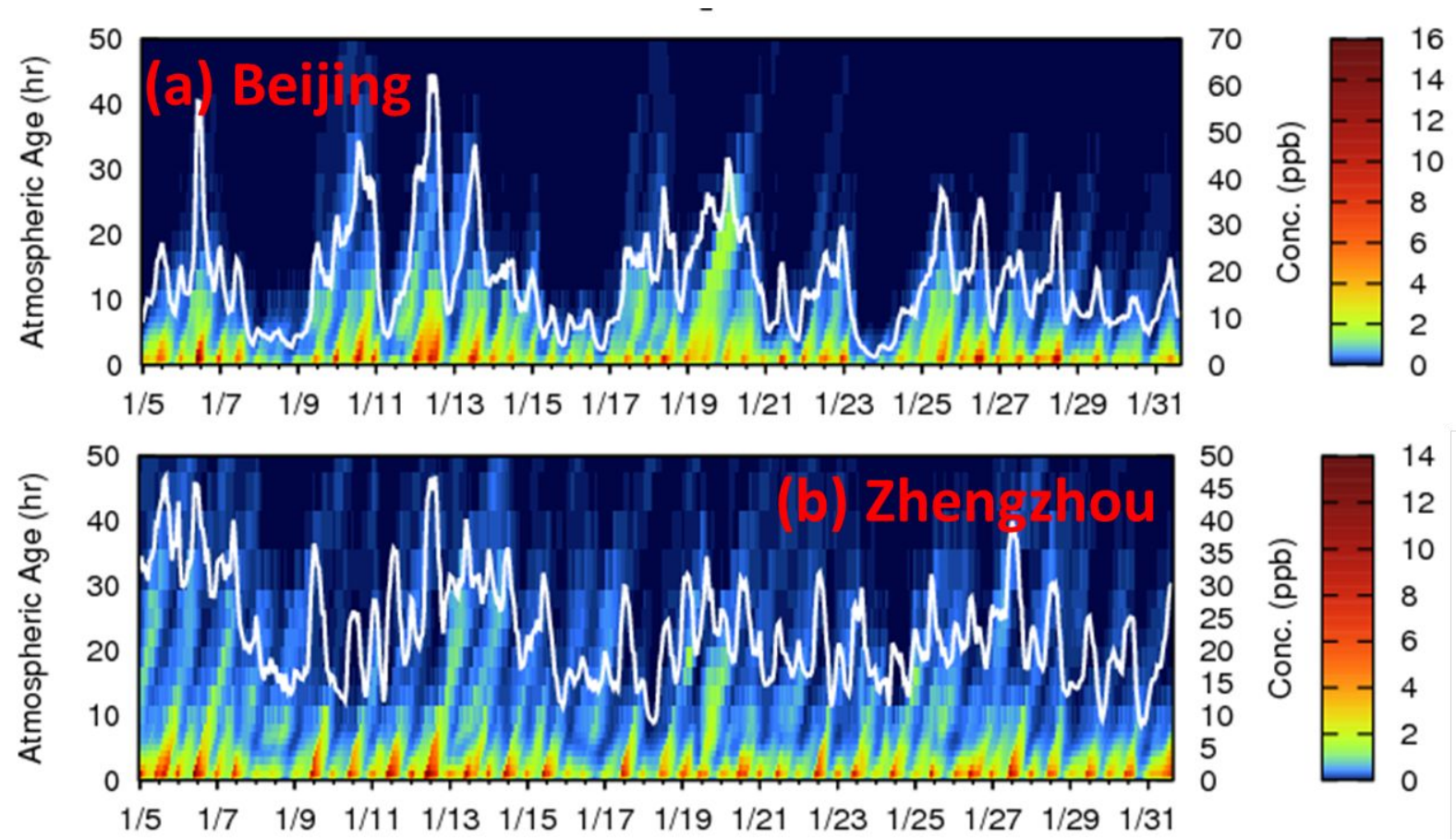

36 Figure $\mathrm{S} 4$ Evolution of atmospheric age distribution of $\mathrm{SO}_{2}$ concentrations in (a) Beijing and (b)

37 Zhengzhou from January 5 to 31,2013 . White lines (secondary y-axis) shows total

38 concentrations of $\mathrm{PM}_{2.5} \mathrm{NO}_{3}^{-}$. The results were assembled from five sets of simulations with

39 different age bin advance frequencies (1, 3, 6, 8 and 12 hours).

40

41 

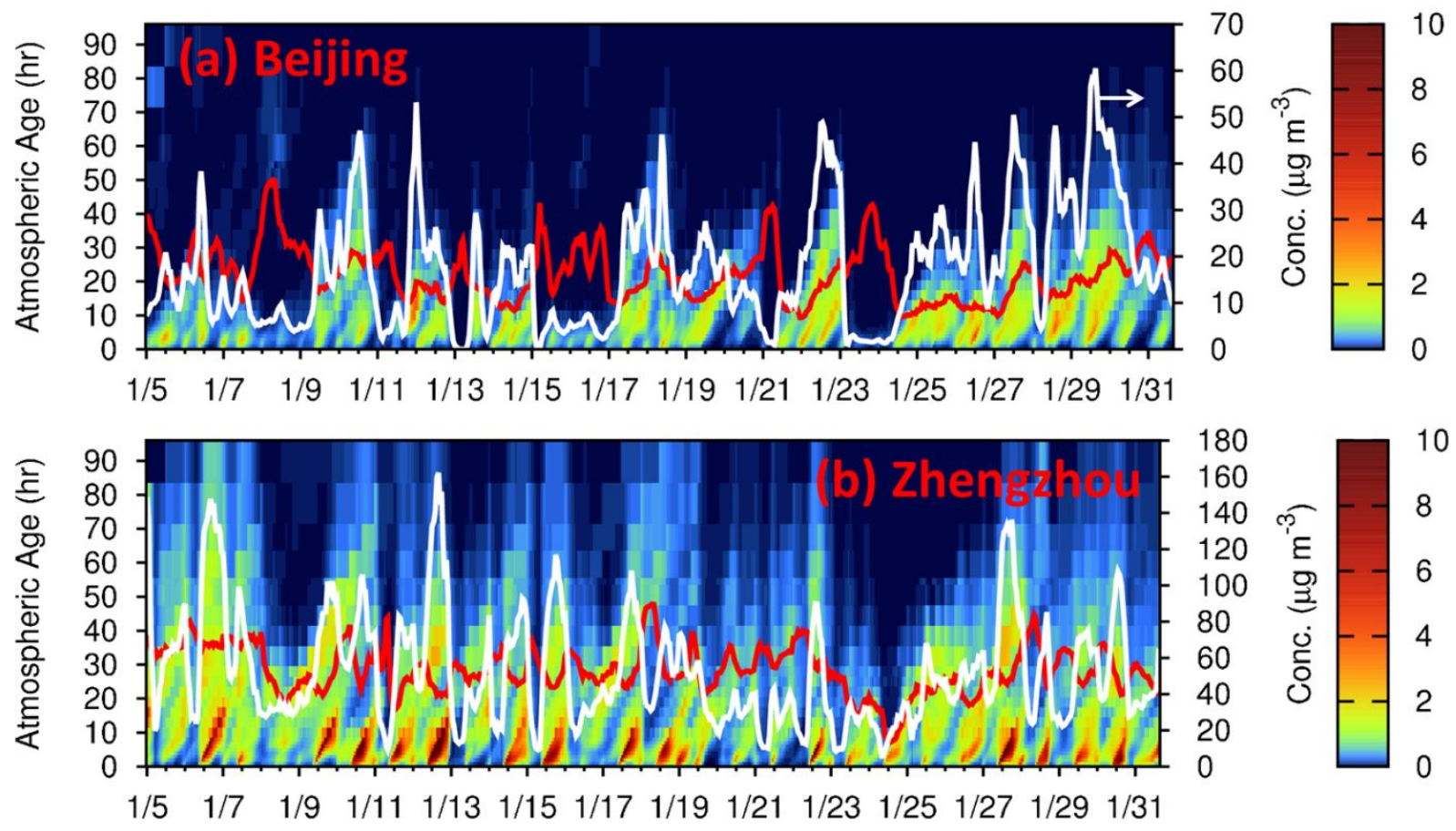

Figure S5 Evolution of atmospheric age distribution of primary $\mathrm{PM}_{2.5}$ nitrate $\left(\mathrm{NO}_{3}{ }^{-}\right)$mass

44 concentrations in (a) Beijing and (b) Zhengzhou from January 5 to 31, 2013. White lines

45 (secondary y-axis) shows total concentrations of $\mathrm{PM}_{2.5} \mathrm{NO}_{3}{ }^{-}$. Red lines indicate the mean

46 atmospheric age (primary y-axis). The results were assembled from five sets of simulations with

47 different age bin advance frequencies (1, 3, 6, 8 and 12 hours). 

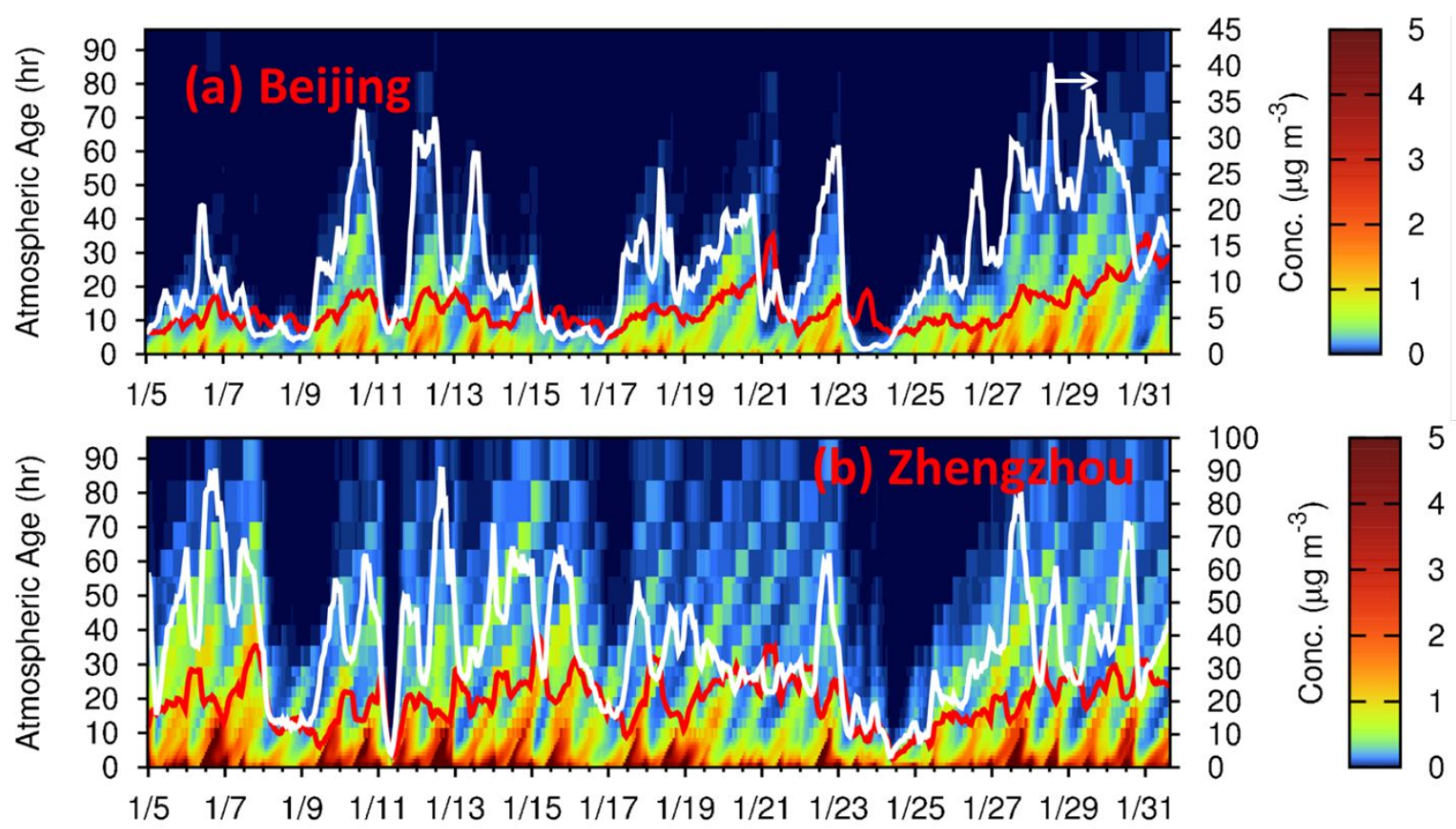

Figure S6 Evolution of atmospheric age distribution of $\mathrm{PM}_{2.5}$ ammonium ion $\left(\mathrm{NH}_{4}^{+}\right)$mass

51 concentrations in (a) Beijing and (b) Zhengzhou from January 5 to 31, 2013. White lines

52 (secondary y-axis) shows total concentrations of $\mathrm{PM}_{2.5} \mathrm{NH}_{4}^{+}$. Red lines indicate the mean

53 atmospheric age (primary y-axis). The results were assembled from five sets of simulations with

54 different age bin advance frequencies (1, 3, 6, 8 and 12 hours). 

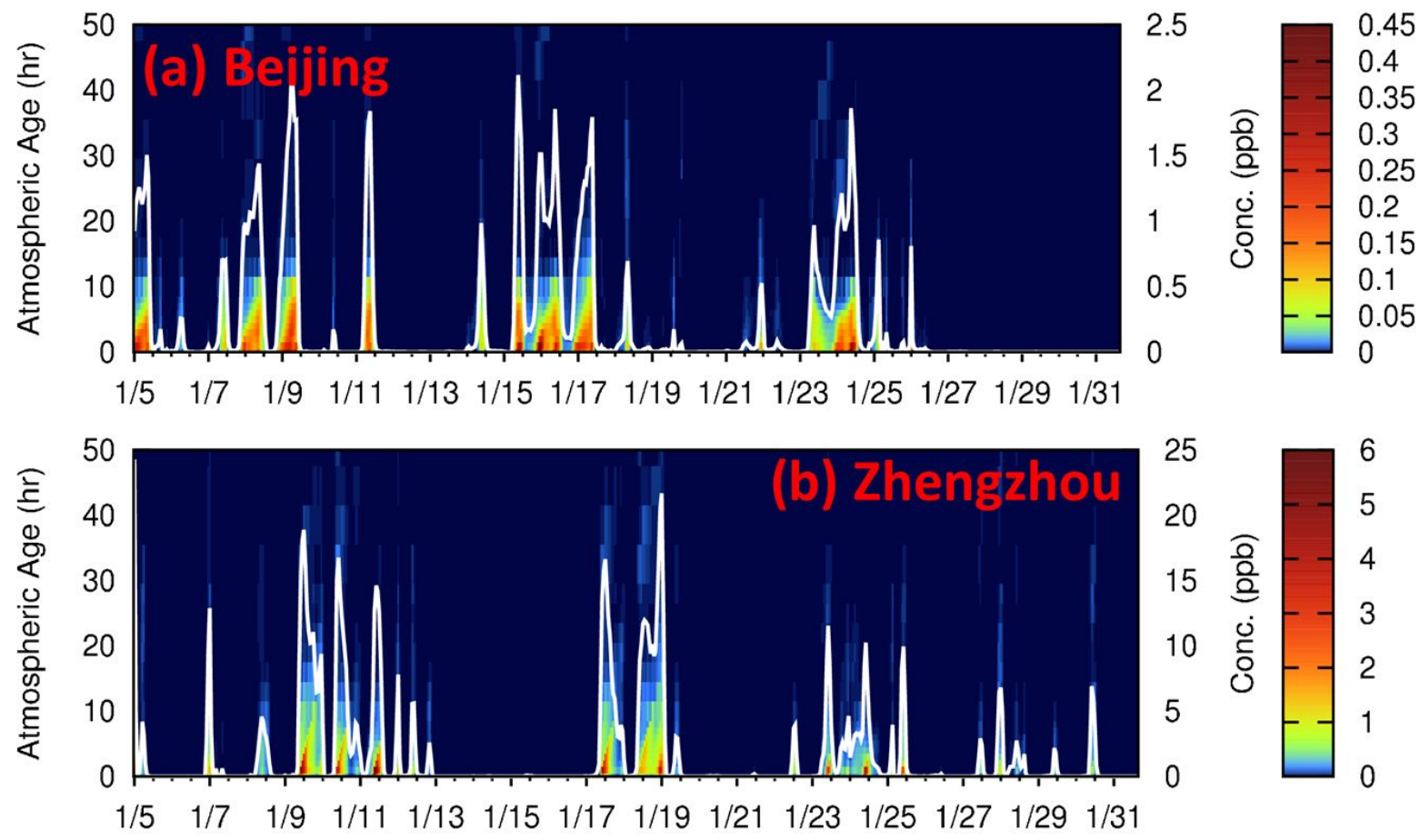

56 Figure $\mathrm{S} 7$ Evolution of atmospheric age distribution of $\mathrm{NH}_{3}$ concentrations in (a) Beijing and (b)

57 Zhengzhou from January 5 to 31,2013 . White lines (secondary y-axis) show the total

58 concentrations of $\mathrm{NH}_{3}(\mathrm{ppb})$. The results were assembled from five sets of simulations with

59 different age bin advance frequencies (1, 3, 6, 8 and 12 hours). 

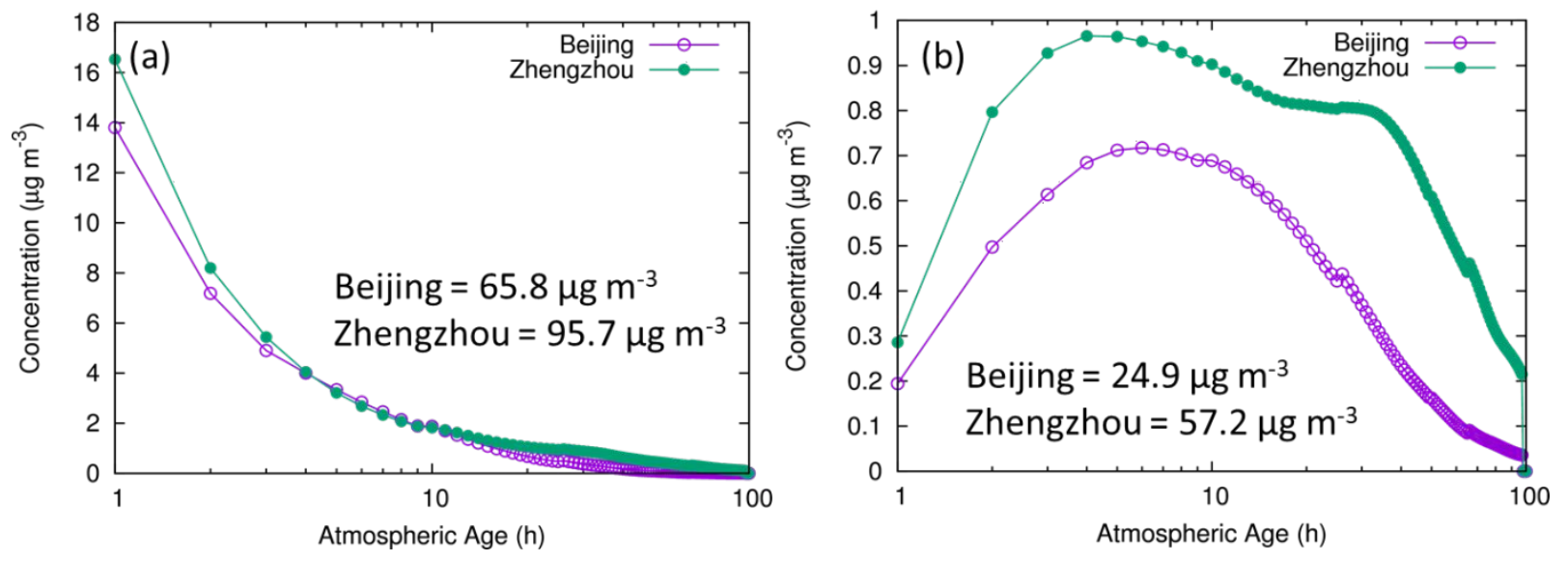

61 Figure S8 Concentration of (a) primary PM2.5 and (b) PM2.5 sulfate in Beijing and Zhengzhou 62 between January 5 and January 31, 2013, as a function of their atmospheric age.

63

64 

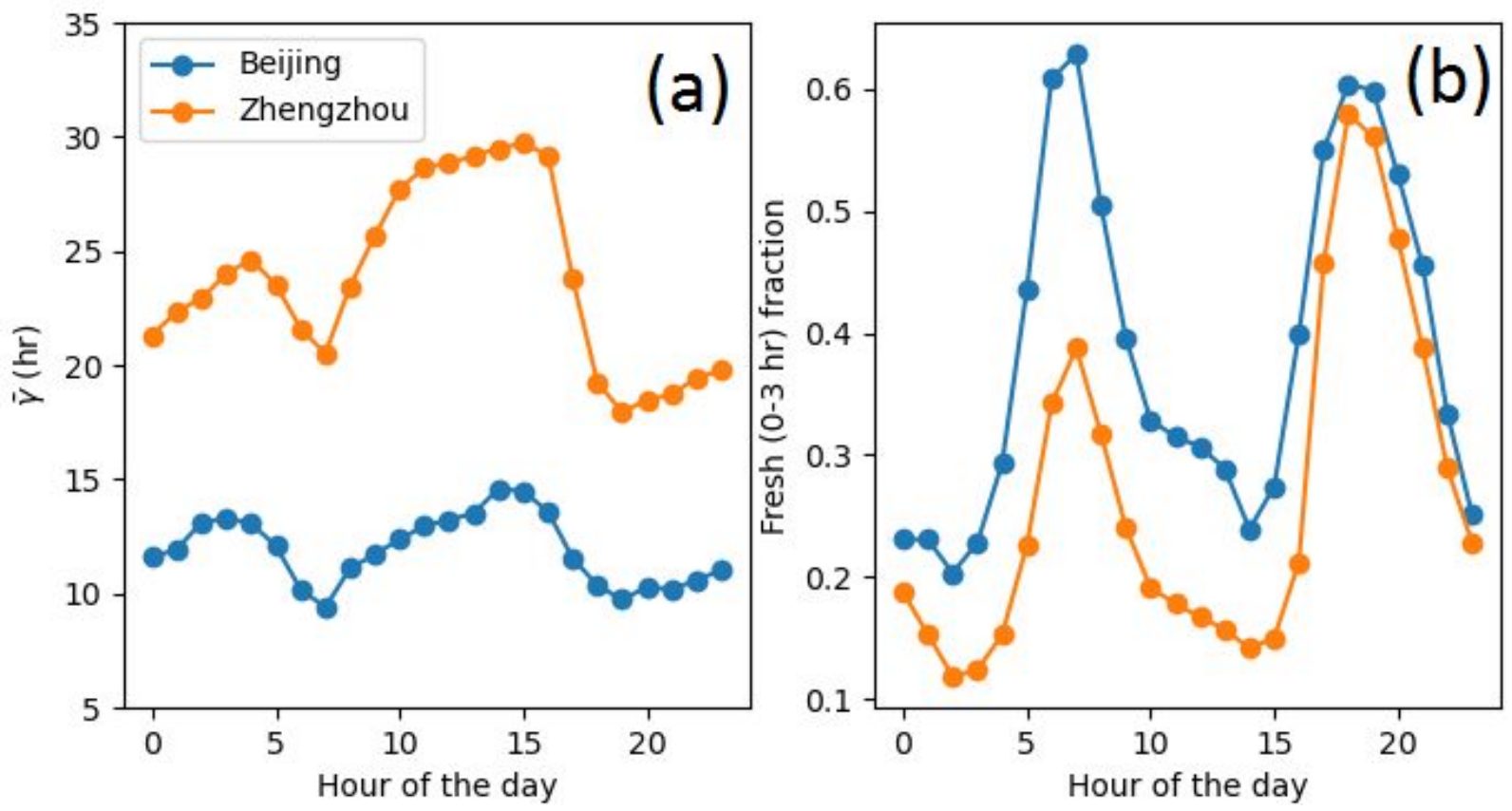

66 Figure S9 Diurnal variation of (a) mean atmospheric age and (b) mass fraction of 0-3 hr fresh 67 particles for PPM.

68 

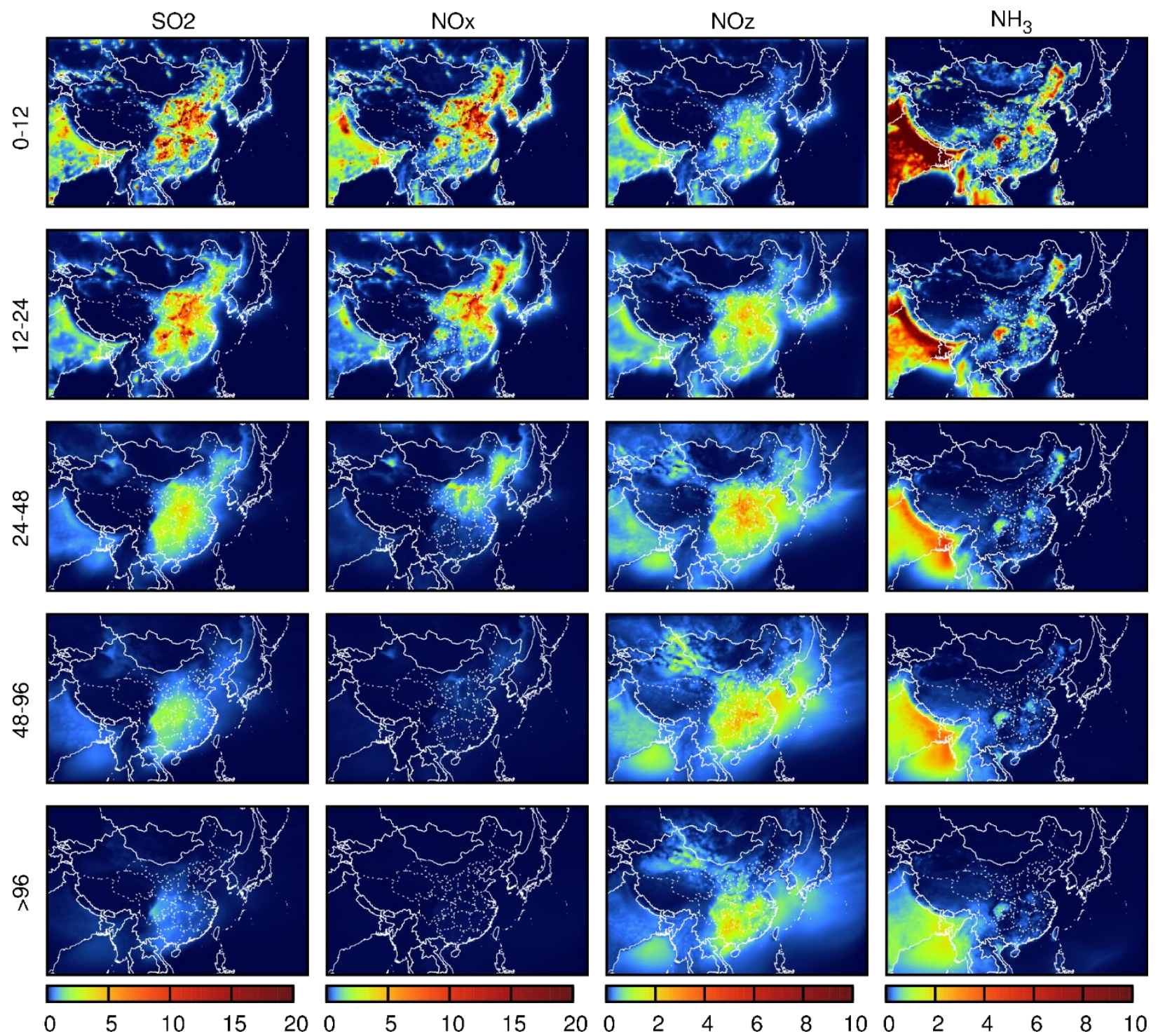

Figure $\mathrm{S} 10$ Regional distribution of $\mathrm{SO}_{2}, \mathrm{NO}_{\mathrm{x}}, \mathrm{NO}_{z}$, and $\mathrm{NH}_{3}$ concentrations for different

71 atmospheric age groups January 2013. The results are based on the simulation with $\Delta \tau_{P}=\Delta \tau_{s}=12$

72 hours. Units are ppb. $\mathrm{NO}_{z}$ is the sum of other nitrogen oxides in the model, mainly $\mathrm{HNO}_{3}, \mathrm{PAN}$,

$73 \mathrm{PAN}_{2}, \mathrm{HNO}_{4}, \mathrm{RNO}_{3}$, and $\mathrm{HONO}$. 

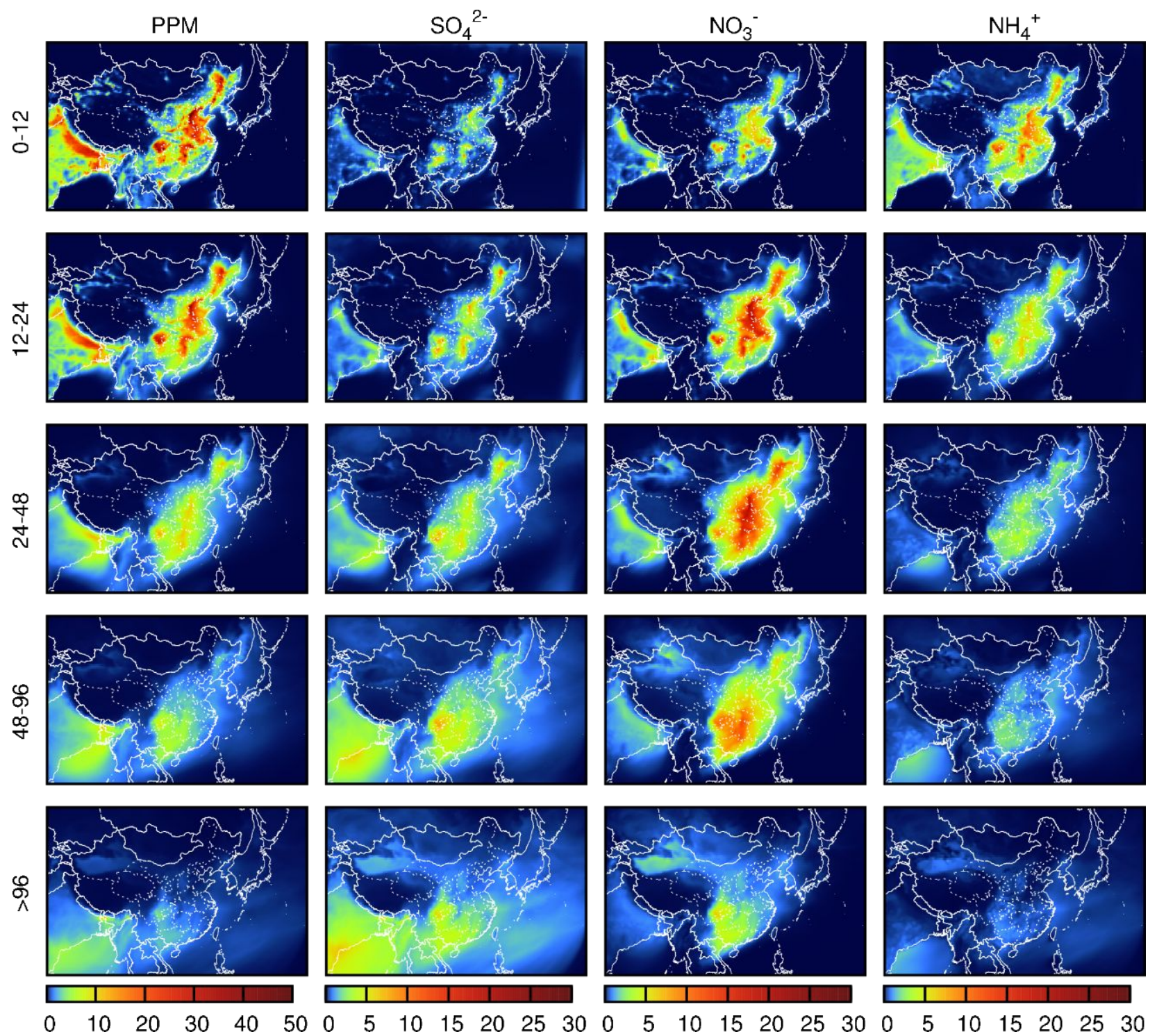

75 Figure $\mathrm{S} 11$ Regional distribution of $\mathrm{PPM}, \mathrm{SO}_{4}{ }^{2-}, \mathrm{NO}_{3}{ }^{-}$and $\mathrm{NH}_{4}{ }^{+}$concentrations for different

76 atmospheric age groups for January 2017. The results are based on the simulation with $\Delta \tau_{P}=\Delta \tau_{s}$

$77=12$ hours. Units are $\mu \mathrm{g} \mathrm{m}^{-3}$. 

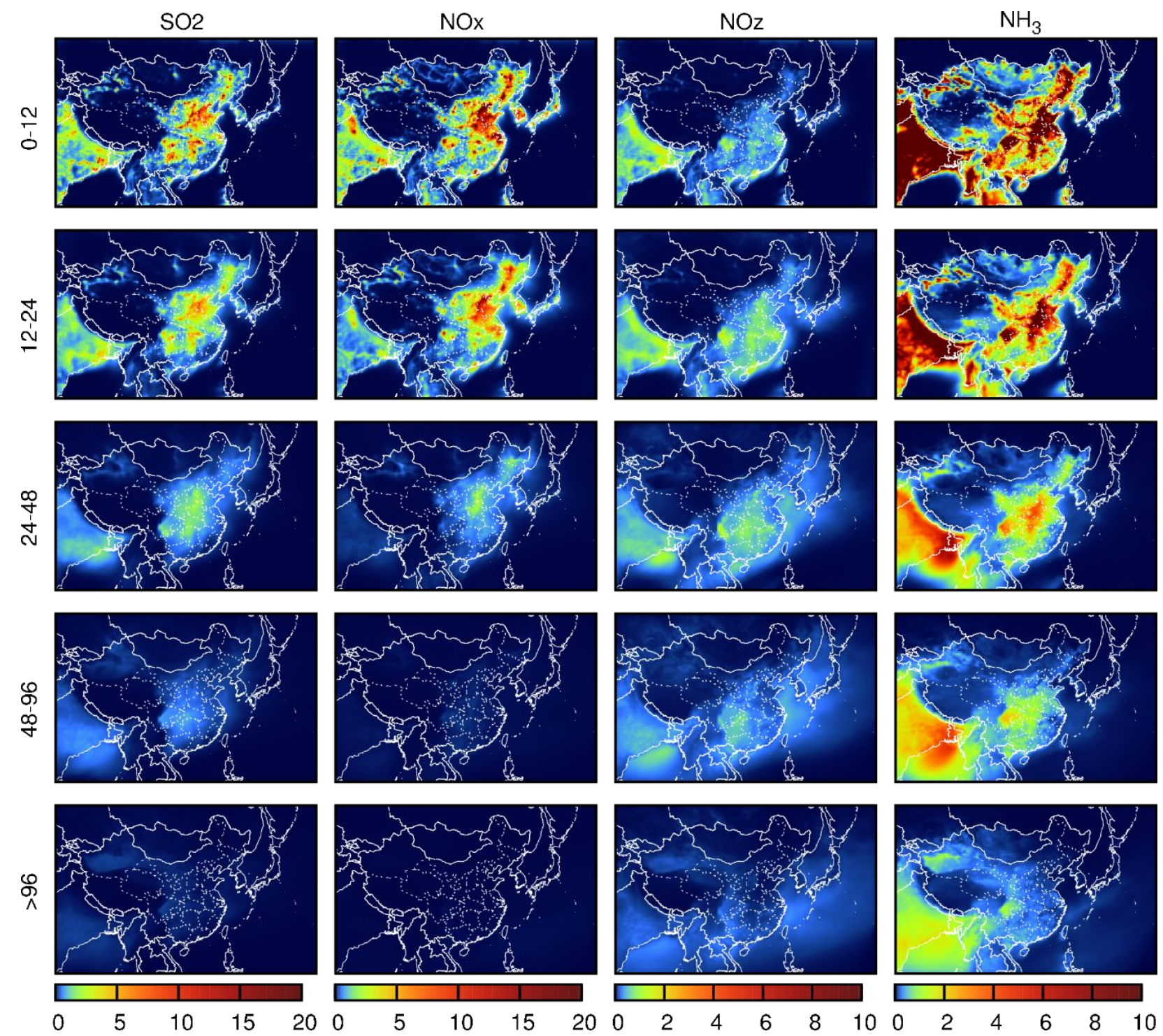

79 Figure $\mathrm{S} 12$ Regional distribution of $\mathrm{SO}_{2}, \mathrm{NO}_{\mathrm{x}}, \mathrm{NO}_{\mathrm{z}}$, and $\mathrm{NH}_{3}$ concentrations for different

80 atmospheric age groups for January 2017. The results are based on the simulation with $\Delta \tau_{P}=\Delta \tau_{s}$

$81=12$ hours. Units are ppb. $\mathrm{NO}_{z}$ is the sum of other nitrogen oxides in the model, mainly $\mathrm{HNO}_{3}$,

82 PAN, $\mathrm{PAN}_{2}, \mathrm{HNO}_{4}, \mathrm{RNO}_{3}$, and $\mathrm{HONO}$. 
86 Table S1 Average atmospheric age represented by each age bin for simulations with different age

87 bin advance intervals

\begin{tabular}{c|ccccc}
\hline \multirow{2}{*}{ Age Bins } & \multicolumn{5}{|c}{ Age Bin Advance Interval (hr) } \\
& 1 & 3 & 6 & 8 & 12 \\
\hline 0 & 0.5 & 1.5 & 3 & 4 & 6 \\
1 & 1.5 & 4.5 & 9 & 12 & 18 \\
2 & 2.5 & 7.5 & 15 & 20 & 30 \\
3 & 3.5 & 10.5 & 21 & 28 & 42 \\
4 & 4.5 & 13.5 & 27 & 36 & 54 \\
5 & 5.5 & 16.5 & 33 & 44 & 66 \\
6 & 6.5 & 19.5 & 39 & 52 & 78 \\
7 & 7.5 & 22.5 & 45 & 60 & 90 \\
8 & 8.5 & 25.5 & 51 & 68 & 102 \\
9 & 9.5 & 28.5 & 57 & 76 & 114 \\
\hline
\end{tabular}

88 *The grey shaded cells indicate the results used in the final analysis of the age distribution of

89 primary and secondary PM. 